Check for updates

Cite this: RSC Adv., 2018, 8, 11455

Received 7th February 2018

Accepted 8th March 2018

DOI: $10.1039 / \mathrm{c} 8 \mathrm{ra01199k}$

rsc.li/rsc-advances

\title{
Investigation on the structural, morphological, electronic and photovoltaic properties of a perovskite thin film by introducing lithium halide $\uparrow$
}

\author{
Zhenhua Lin,,$^{\mathrm{a}}$ Hai Zhu,,$^{\mathrm{b}}$ Long Zhou, ${ }^{\mathrm{a}}$ Jianhui Du, ${ }^{\mathrm{a}}$ Chunfu Zhang, (D) \\ Qing-Hua Xu, ${ }^{b}$ Jingjing Chang, (D) *a Jianyong Ouyang (D) ${ }^{c}$ and Yue Hao ${ }^{a}$
}

\begin{abstract}
The performance of perovskite solar cells (PSCs) including device efficiency and stability is mainly dependent on the perovskite film properties which are critically related to the organic cations used. Herein, we studied the role that the inorganic lithium (Li) cation played in perovskite thin films and its influence on crystal growth, film properties, and device performance. We found that within the threshold limit of a 1.0\% molar ratio, the Li dopant had a positive effect on the film formation and properties. However, after replacing more $\mathrm{MA}^{+}$with $\mathrm{Li}^{+}$, the device performance was degraded significantly with reduced short-circuit current density $\left(J_{s c}\right)$ and fill factor $(F F)$ values. With a doping ratio of $10 \mathrm{~mol} \%$, the film morphology, crystallinity, photophysical, and electronic properties totally changed due to the unstable nature of the Li doped, distorted 3-D perovskite structure. The Li doping mechanism was discussed, and it was thought to contain two different doping mechanisms. One is interstitial doping at the much lower doping ratio, and the other is substitutional doping for the MA cation at the higher doping ratio.
\end{abstract}

\section{Introduction}

Organometal halide perovskite solar cells (PSCs) have attracted much attention during the past few years due to their appealing features such as optimal band gap, high absorption coefficients, small exciton binding energy, and long carrier lifetimes and exciton diffusion length compared to organic semiconductors. ${ }^{1-9}$ Perovskite solar cells have achieved much progress since 2012, and the power conversion efficiency (PCE) of PSC devices has achieved $16-21 \%$ by using vapor deposition, two-step sequential deposition or solvent engineering with one step deposition based on a planar heterojunction structure. ${ }^{\mathbf{1 0 , 1 1}}$ Moreover, the PSC efficiency could be further enhanced by using compositional engineering, ${ }^{12,13}$ interface engineering, ${ }^{14-16}$ and other new methods. ${ }^{17,18}$ Up to now, the reported PCEs have reached up to $22.7 \%$, and this value has exceeded the expectation of the commercial energy conversion efficiency threshold. ${ }^{19}$

\footnotetext{
${ }^{a}$ State Key Laboratory of Wide Band Gap Semiconductor Technology, Shaanxi Joint Key Laboratory of Graphene, School of Microelectronics, Xidian University, 2 South Taibai Road, Xi'an, China 710071. E-mail: jjingchang@xidian.edu.cn

${ }^{b}$ Department of Chemistry, National University of Singapore, 3 Science Drive 3, Singapore 117543

${ }^{\circ}$ Department of Materials Science and Engineering, National University of Singapore, 7 Engineering Drive 1, Singapore 117574

$\dagger$ Electronic supplementary information (ESI) available: XRD spectra, band gap of doped perovskite, steady-state PCE output. See DOI: 10.1039/c8ra01199k

\$ These authors contributed equally to this work.
}

The perovskite thin film morphology and properties could be affected by the precursors used, deposition conditions, and post-treatment conditions. ${ }^{20,21}$ Among them, the precursors used could be well tuned by blending different lead compounds including halide and non-halide compound and organic cations with different ratios. The band gap and electronic properties could be easily tailored by choosing different metal cations like (lead $(\mathrm{Pb})$, tin ( $\mathrm{Sn})$ ), ${ }^{22-24}$ different inorganic anions like (bromine $(\mathrm{Br})$, chlorine $(\mathrm{Cl})),{ }^{25-29}$ and organic ligands like ethylammonium and formamidinium..$^{\mathbf{1 0 3 0 - 3 3}}$ For example, the Br substituted $\mathrm{CH}_{3} \mathrm{NH}_{3} \mathrm{PbI}_{3}\left(\mathrm{MAPbI}_{3}\right)$ exhibited increased band gap and enhanced open-circuit voltage $\left(V_{\mathrm{oc}}\right)$ in the PSC devices. ${ }^{25-29}$ The Formamidinium substituted $\mathrm{MAPbI}_{3}$ showed decreased band gap and enhanced light absorption. ${ }^{\mathbf{1 0 , 3 0 - 3 3}}$ Moreover, the alkali metal ion (sodium $\left(\mathrm{Na}^{+}\right)$or potassium $\left(\mathrm{K}^{+}\right)$) dopants could significantly enhance the crystal size and crystallinity, and reduce the charge recombination, resulting in significantly enhanced short-circuit current $\left(J_{\mathrm{sc}}\right)$ and PCE. ${ }^{\mathbf{1 2 , 3 4}}$

Previously, lithium (Li) salts have been applied in dyesensitized solar cells (DSSCs) and lithium-sulfur batteries, and $\mathrm{Li}$ ions have been shown to play important roles in power generating in the devices. ${ }^{35-37}$ Meanwhile, Li salts as doping sources to enhance the hole or electron transport layer conductivity have been reported extensively. It was found that the solar cell performance was enhanced a lot after using $\mathrm{Li}$ doped spiro-OMeTAD compound or titanium oxide $\left(\mathrm{TiO}_{2}\right)$ interlayer in perovskite solar cells. ${ }^{38-40}$ However, the effect of $\mathrm{Li}$ dopant on the perovskite thin film properties as well as the 
photophysical properties has not been investigated, and it is necessary to understand these mechanisms to achieve high performance perovskite solar cells. In order to investigate the effect on the crystal morphology and charge transport properties, lithium iodine (LiI), or lithium bromide ( $\mathrm{LiBr}$ ) dopants were intentional introduced into the precursors.

In this study, the alkaline metal dopants (LiI, or LiBr) were intentionally incorporated into the $\mathrm{CH}_{3} \mathrm{NH}_{3} \mathrm{PbI}_{3}$ precursor solution prior to the thin film formation. Different molar ratios of LiI or LiBr were introduced into the precursor solutions with respect to the $\mathrm{PbI}_{2}$. We investigated the lithium dopant effect on the perovskite thin film formation, absorption, charge transport, and photovoltaic properties. It was found that proper amount of lithium dopant can significantly alter the optical properties and enhance $V_{\text {oc }}$. Meantime, the $J_{\text {sc }}$ showed slightly increase firstly and then sharp decrease when gradually increasing the Li content. Unlike the DSSC devices, it was found that the excess Li ion can enhance the charge carrier density, which is desirable for high performance device.

\section{Results and discussion}

The thin film crystallinity has been reported that it could affect the efficiency of charge dissociation, charge transport, and charge diffusion length. Thus, thin film crystallinity was investigated by X-ray diffraction (XRD) based on $\mathrm{CH}_{3} \mathrm{NH}_{3} \mathrm{PbI}_{3}$ films with different Li doping ratios. As shown in Fig. 1, the XRD spectra of the $\mathrm{CH}_{3} \mathrm{NH}_{3} \mathrm{PbI}_{3}$ thin films showed strong diffraction peaks around $14.2^{\circ}, 28.5^{\circ}$, and $31.9^{\circ}$ which can be assigned to (110), (220), and (310) crystal planes of tetragonal perovskite, respectively, indicating a highly crystalline nature with (110) plane preferentially oriented. The diffraction peak around $12.7^{\circ}$ was arising from $\mathrm{PbI}_{2}$ peak. When Li doping ratio increased to $10.0 \%$, the diffraction peaks at around $6.4^{\circ}, 9.1^{\circ}, 27.1^{\circ}$ and $33.1^{\circ}$ were observed, and they should belong to the mixed phase of perovskite $\mathrm{MA}_{1-x} \mathrm{Li}_{x} \mathrm{PbI}_{3}$. This indicates that a new phase
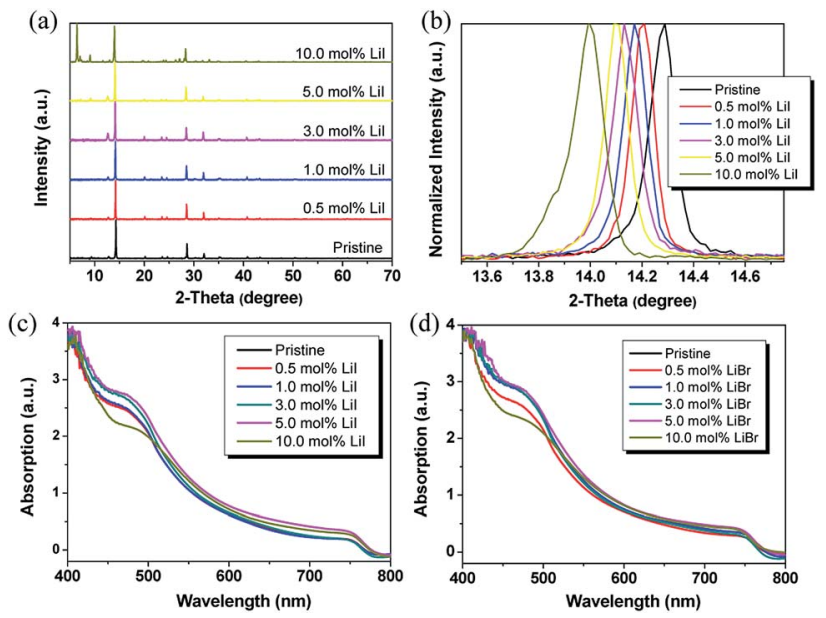

Fig. 1 (a) XRD spectra of perovskite thin films with different molar doping ratios of Lil. (b) Zoom-in spectra for diffraction peak around $14^{\circ}$. UV-vis absorption spectra of perovskite thin films with different molar doping ratios of $\mathrm{Lil}$ (c) and $\mathrm{LiBr}(\mathrm{d})$.
$\mathrm{MA}_{1-x} \mathrm{Li}_{x} \mathrm{PbI}_{3}$ was formed in the thin films. The crystal size could be estimated by the Scherrer equation, and the value was about $170 \mathrm{~nm}$ for $10 \% \mathrm{Li}$ doped thin film due to the decreased full width at half maximum (FWHM) of the diffraction peaks compared to $\mathrm{MAPbI}_{3}$ with a crystal size of $98 \mathrm{~nm}$. It should also be noted that when gradually increasing the LiI ratio, the diffraction peak shifted to lower angles, indicating that the crystal lattice was expanded, which could be explained by the interstitial doping effect of $\mathrm{Li}$ cation since the ionic radius of $\mathrm{Li}^{+}$ is much smaller than $\mathrm{MA}^{+}$. This is similar with $\mathrm{Na}^{+}$or $\mathrm{K}^{+}$cation doping effect reported previously. ${ }^{12}$ Meanwhile, the diffraction intensity of (110) peaks firstly decreased at lower doping ratio $(\leq 3.0 \%)$, and then increased at higher doping ratio ( $\geq 5.0 \mathrm{~mol} \%$ ), indicating that the crystal growth process was changed when doping ratio of $\mathrm{Li}^{+}$above $5.0 \%$ (Fig. $\mathrm{S} 1 \dagger$ ). The case for $\mathrm{LiBr}$ is different as the $\mathrm{Br}^{-}$is smaller than $\mathrm{I}^{-}$, which could cause a crystal contraction (Fig. $\mathrm{S} 2 \dagger$ ). This is opposite with the $\mathrm{Li}^{+}$cation. Hence, the diffraction peak did not show further shift with increasing the $\mathrm{Br}^{-}$doping ratios.

The thin film absorption spectra with different LiI and $\mathrm{LiBr}$ ratios were shown in Fig. $1 \mathrm{c}$ and $\mathrm{d}$. The $\mathrm{MAPbI}_{3}$ thin film had strong absorption from the visible range down to the nearinfrared wavelengths with the absorption onset at $c a$. 780$785 \mathrm{~nm}$ (optical band gap $=1.58 \mathrm{eV}$ ). The measured shape was consistent with the literature reported results. ${ }^{20}$ The long absorption onset showed slightly blue-shift for the Li doped films compared to the pristine $\mathrm{CH}_{3} \mathrm{NH}_{3} \mathrm{PbI}_{3}$ thin film. The band gap determined by the onset was about $\sim 1.61-1.62 \mathrm{eV}$ for $0.5-$ $5.0 \mathrm{~mol} \% \mathrm{LiBr}$ doped thin film, and it showed a $0.01-0.02 \mathrm{eV}$ blue-shift compared to the pristine perovskite.

This tread could be explained by the doping mechanism. When the Li doping ratio was small, the Li ion mainly adopted interstitial doping since the $\mathrm{Li}$ ion $(76 \mathrm{pm})$ is much smaller than MA cation (119 pm). ${ }^{12}$ In this case, the Li ion did not occupy the MA position but only occupied the empty site and enhanced the carrier density, resulting in slightly decreased band gap may be due to the impurity band caused by the Li doping and orbital coupling with neighbor Pb-I orbitals (Fig. S3†). When the Li doping ratio increased above $5 \mathrm{~mol} \%$, the excess $\mathrm{Li}$ ions would substitute the MA cations, and cause the crystal structure distortion. According to the density functional theory (DFT) calculation results, the fully Li substituted perovskite thin film showed a large band gap of around $1.79 \mathrm{eV}$ which was much larger compared to MA based perovskite thin film. ${ }^{41}$ Then, the band gap increased again (Fig. S3†). However, in the $3 \mathrm{D}$ perovskite structure, when doping with some elements or functional groups with larger or smaller ionic radius, the crystal structure usually has the distortions. In this case, a semiempirical approach based on the Goldschmidt tolerance factor $\tau$ is employed to evaluate the stability of the structure. It is known empirically that $3 \mathrm{D}$ perovskite should form when the tolerance factor falls within a narrower range $\tau=0.7-1.1$. And according to the DFT calculation in the literature, the Li cation doping produces a tolerance factor below 0.7 , which makes it unstable towards stable $3 \mathrm{D}$ perovskite structure. ${ }^{41}$

The perovskite thin film morphology was further investigated by field-emission scanning electron microscopy (FESEM). 
As shown in Fig. 2, the prepared thin films with different $\mathrm{Li}$ doping ratios showed much uniform and full surface coverage with regular crystallites. The good thin film uniformity and coverage suggested a homogenous nucleation on the PEDOT:PSS surface due to the proper control on the crystal formation and growth. SEM images showed the corresponding morphology evolution of perovskite films upon changing the $\mathrm{Li}$ ratio. The pristine film was compact and conformal. It seemed that the films could tolerate the $\mathrm{Li}^{+}$ions to the precursor up to around 3.0 mol\% before any obvious morphology change occurred, and the film still kept compact and uniform. This is consistent with the XRD results. However, when the ratio increased to $5.0 \mathrm{~mol} \%$, some newly formed phase crystals appeared between the $\mathrm{MAPbI}_{3}$ grains, and the morphology changed. When the Li ratio further increased to $10.0 \mathrm{~mol} \%$, the large nanoplate-like regular crystals were formed on the substrates, indicating a different crystal behavior upon adding the $\mathrm{Li}$ ions. It was thought that the $\mathrm{Li}$ cations enhanced the $\mathrm{MAPbI}_{3}$ crystallization, reduced the nucleation density and favored a homogeneous nucleation on the substrates. However, it also produced proper pinholes between the crystal grains which are harmful for the solar cell device performance due to increased charge recombination and leakage. Compared to LiI based thin films, it was found that the crystal morphology was more uniform after Br substitution occurred. Previously, it has been reported that, the $\mathrm{Br}$ ion could enhance the thin film properties due to retarded crystallization. Fig. 2(l) shows the cross-section SEM image of perovskite device based on $0.5 \mathrm{~mol} \%$ LiI doped perovskite, and a dense and uniform perovskite layer could be identified. Moreover, the perovskite crystals were direct contact with PEDOT:PSS and PCBM layers, indicating a high quality of the perovskite film, which could contribute to enhancing the photovoltaic performance.
The planar heterojunction device structure with a configuration of ITO/PEDOT:PSS/perovskite/PCBM/BCP/Ag was used. Current density $(J)$-voltage $(V)$ characteristics of the device fabricated with the same film formation condition has been shown in Fig. 3. The $V_{\mathrm{oc}}, J_{\mathrm{sc}}$, fill factor (FF), and PCE of all devices are summarized in Table 1 . As can been seen, the Li incorporation had a large influence on the device performance. The device exhibited a comparable efficiency of $13.1 \%$ for pristine thin film with $J_{\mathrm{sc}}, V_{\mathrm{oc}}$, and FF of $19.6 \mathrm{~mA} \mathrm{~cm}{ }^{-2}, 0.93 \mathrm{~V}$, and 0.72 , respectively. The $0.5 \mathrm{~mol} \% \mathrm{LiI}$ doped $\mathrm{MAPbI}_{3}$ showed slight increase in PCEs due to enhanced $J_{\mathrm{sc}}$ and $V_{\mathrm{oc}}$, indicating that the impurity threshold limit of the films was $0.5 \%$ molar ratio. The corresponding $J_{\mathrm{sc}}, V_{\mathrm{oc}}, \mathrm{FF}$ and PCE were $20.1 \mathrm{~mA}$ $\mathrm{cm}^{-2}, 0.97 \mathrm{~V}, 0.73$, and $14.2 \%$, respectively. When the doping ratio increased to and $1.0 \mathrm{~mol} \%$, and even up to $5 \mathrm{~mol} \%, J_{\mathrm{sc}}$ and FF gradually reduced. The resulting PCE also decreased to $13.0 \%, 8.7 \%$ and $5.4 \%$ for $1 \%, 3 \%$ and $5 \%$ molar ratio doped film, respectively. The lower $J_{\mathrm{sc}}$ and FF indicated a high series resistance $\left(R_{\mathrm{S}}\right)$ and large charge recombination in the device, which may be due to Li-induced charge traps in the thin film that quenched the photo-generated charge carriers. The PCE of $\mathrm{MAPbI}_{3}$ devices further decreased to $4.8 \%$ for the devices with $10 \%$ molar doping ratio of samples. And the decrement of PCE was reflected by a reduction of $V_{\text {oc }}$ due to structure change induced by the Li impurities. The $J_{\text {sc }}, V_{\text {oc }}$, and FF were $10.5 \mathrm{~mA}$ $\mathrm{cm}^{-2}, 0.96 \mathrm{~V}$, and 0.48 , respectively.

It is believed that proper $\mathrm{Br}$ doping could stabilize the $\mathrm{Li}$ doped perovskite, probably due to its decreased atomic radius of $\mathrm{Br}$ compared to I, which can reduce the crystal strain, and hence, the stability was enhanced. The beneficial role of $\mathrm{Br}$ doping provides a practical approach to further enhance the device performance of PSCs. For LiBr case, the $0.5 \mathrm{~mol} \%$ doped perovskite thin film enhanced the $J_{\mathrm{sc}}$ and $V_{\mathrm{oc}}$ to $20.3 \mathrm{~mA} \mathrm{~cm}$
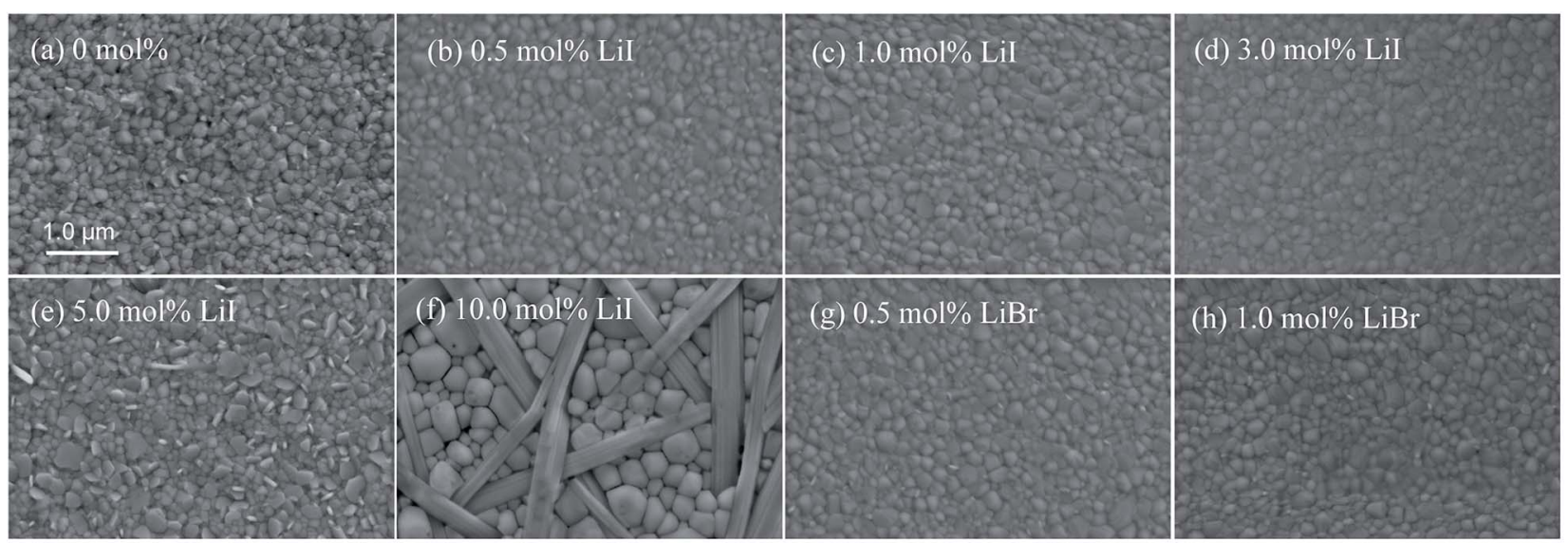

(g) $0.5 \mathrm{~mol} \% \mathrm{LiBr}$
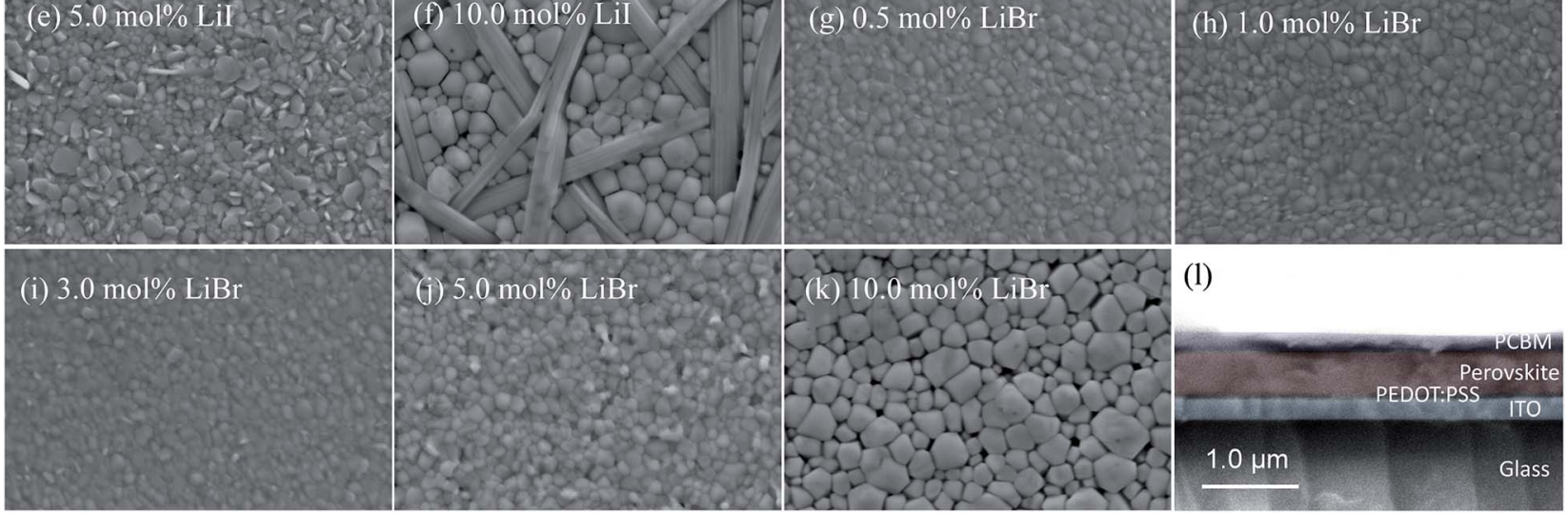

(1)

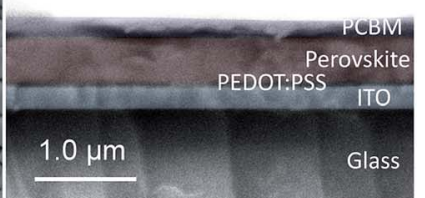

Fig. 2 (a)-(k) Top-view SEM images of perovskite thin films based different ratios of Li doping. (l) Cross-section image of perovskite device based on 0.5 mol\% Lil doped perovskite. 

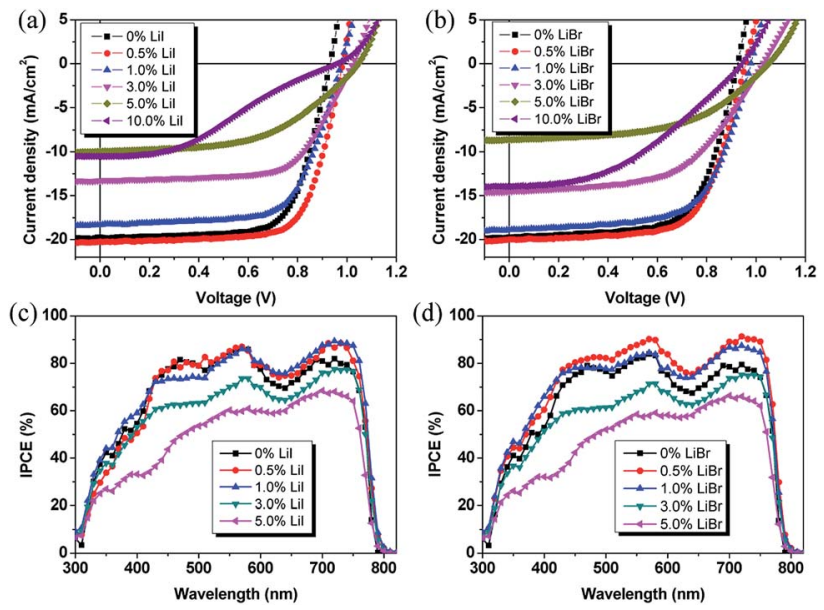

Fig. 3 J-V characteristics of different Lil (a) and $\mathrm{LiBr}$ (b) doped perovskite thin film devices. IPCE spectra of perovskite solar cells based on different Lil (c) and $\mathrm{LiBr}$ (d) dopants.

and $0.97 \mathrm{~V}$, respectively. Hence, the resulting PCE was enhanced to $14.1 \%$. Further increasing the $\mathrm{LiBr}$ doping ratio, the $J_{\mathrm{sc}}$ decreased from $19.6 \mathrm{~mA} \mathrm{~cm}^{-2}$ for $\mathrm{MAPbI}_{3}$ to $18.8 \mathrm{~mA} \mathrm{~cm}^{-2}, 14.6$ $\mathrm{mA} \mathrm{cm}{ }^{-2}, 10.8 \mathrm{~mA} \mathrm{~cm}^{-2}, 13.9 \mathrm{~mA} \mathrm{~cm}^{-2}$ for Li with a molar ratio of $1 \%, 3 \%, 5 \%$, and $10 \%$, respectively. The $V_{\text {oc }}$ increased from $0.93 \mathrm{~V}$ for $\mathrm{MAPbI}_{3}$ to $0.98 \mathrm{~V}, 1.03 \mathrm{~V}, 1.05 \mathrm{~V}$, and $0.95 \mathrm{~V}$ for Li with a molar ratio of $1 \%, 3 \%, 5 \%$, and $10 \%$ molar ratio, respectively. The FF decreased to $0.66,0.58,0.47$ for $3 \%, 5 \%$, and $10 \%$ molar ratio, respectively, due to increased leakage current and charge recombination. The resulting PCE values were $13.5 \%$ (1.0 mol\%), 9.9\% (3 mol\%), 5.3\% (5 mol\%), and $6.2 \%$ (10 mol\%), respectively. Compared to LiI dopant, the devices with LiBr dopant exhibited higher $J_{\text {sc }}$ which might be ascribed to the improved charge carrier transport and reduced charge recombination induced by impurities-related traps. In order to understand the Li doping effect on the photovoltaic performance of the PSCs, the $R_{\mathrm{S}}$ of the devices was obtained from the $J-V$ curves. The $R_{\mathrm{S}}$ was $3.66 \Omega \mathrm{cm}^{2}$ for the pristine perovskite film based device. It decreased to $2.09 \Omega \mathrm{cm}^{2}$ and $2.13 \Omega \mathrm{cm}^{2}$ for the devices with $0.5 \mathrm{~mol} \% \mathrm{LiI}$ and $\mathrm{LiBr}$ doped $\mathrm{CH}_{3} \mathrm{NH}_{3} \mathrm{PbI}_{3}$, respectively. The steady-state PCE outputs at the maximum power point as a function of time were also checked. As shown in Fig. S4, $\dagger$ the stabilized PCEs were $13.2 \%, 14.3 \%$, and $14.5 \%$ for pristine, $0.5 \mathrm{~mol} \% \mathrm{LiI}$, and $0.5 \mathrm{~mol} \% \mathrm{LiBr}$ doped perovskite, respectively. This indicates that the device results are stable and reliable.

The effect of $\mathrm{Li}$ incorporation was also tested by internal photo-electron conversion efficiency (IPCE) measurements. It is known that the IPCE spectra could provide the information on the components primarily responsible for converting absorbed photos to the collected electrons and holes. As shown in Fig. 3c and $\mathrm{d}$, it could be observed that proper $\mathrm{Li}$ amount could enhance the IPCE. The integrated $J_{\mathrm{sc}}$ were $19.8 \mathrm{~mA} \mathrm{~cm}^{-2}$ and $20.5 \mathrm{~mA} \mathrm{~cm}{ }^{-2}$ for $0.5 \mathrm{~mol} \% \mathrm{LiI}$ and $\mathrm{LiBr}$ doped perovskite device, respectively. When the $\mathrm{Li}$ doping ratio increased to above $1.0 \mathrm{~mol} \%$, the intensity decreased a lot due to the reduced conversion efficiency. This is slightly different from the observed absorption spectra which showed similar absorption for both thin films due to relatively small change in the absorption spectra by this small amount of Li doping.

In order to further elucidate the $\mathrm{Li}$ doping effect on the electronic structure of the $\mathrm{MAPbI}_{3}$, UPS measurement was performed on the pristine perovskite and $10 \%$ molar ratio of $\mathrm{Li}$ doped perovskite composite. The UPS energy levels have been shown in Fig. 4. The secondary electron cutoff of the pristine perovskite film prepared on ITO substrate was located at $17.1 \mathrm{eV}$, and the valence band maximum was located at $1.6 \mathrm{eV}$. Since the energy band of the perovskite was about $1.58 \mathrm{eV}$, it can be concluded that the Fermi level lay close to conduction band edge of the perovskite, indicating an n-type characteristics of the perovskite material. After incorporating Li into the perovskite structure, the secondary electron cutoff slightly shifted by $0.32 \mathrm{eV}$ and $0.38 \mathrm{eV}$ towards the higher binding energy region, indicating an upshift of the Fermi level of about $0.32 \mathrm{eV}$ and $0.38 \mathrm{eV}$ for $10 \mathrm{~mol} \% \mathrm{LiI}$ and $10 \mathrm{~mol} \% \mathrm{LiBr}$, respectively. The large Fermi level shift indicated an increased electron density for the Li doped $\mathrm{MAPbI}_{3}$. And this low performance might be due to the poor junction between $\mathrm{MA}_{1-x} \mathrm{Li}_{x} \mathrm{PbI}_{3}$ and PCBM in the solar cell device. Anyway, we achieved a highly n-doped perovskite $\mathrm{MA}_{1-x} \mathrm{Li}_{x} \mathrm{PbI}_{3}$, and applied it in the perovskite solar cell. And it is expected that the solar cell efficiency could be further improved by choosing spiro/ $\mathrm{MA}_{1-x} \mathrm{Li}_{x} \mathrm{PbI}_{3}$ system due to favorable energy level alignment.

Table 1 Photovoltaic parameters of the perovskite solar cells based on different Li dopants. The average results were derived from 16 perovskite solar cells from two batches

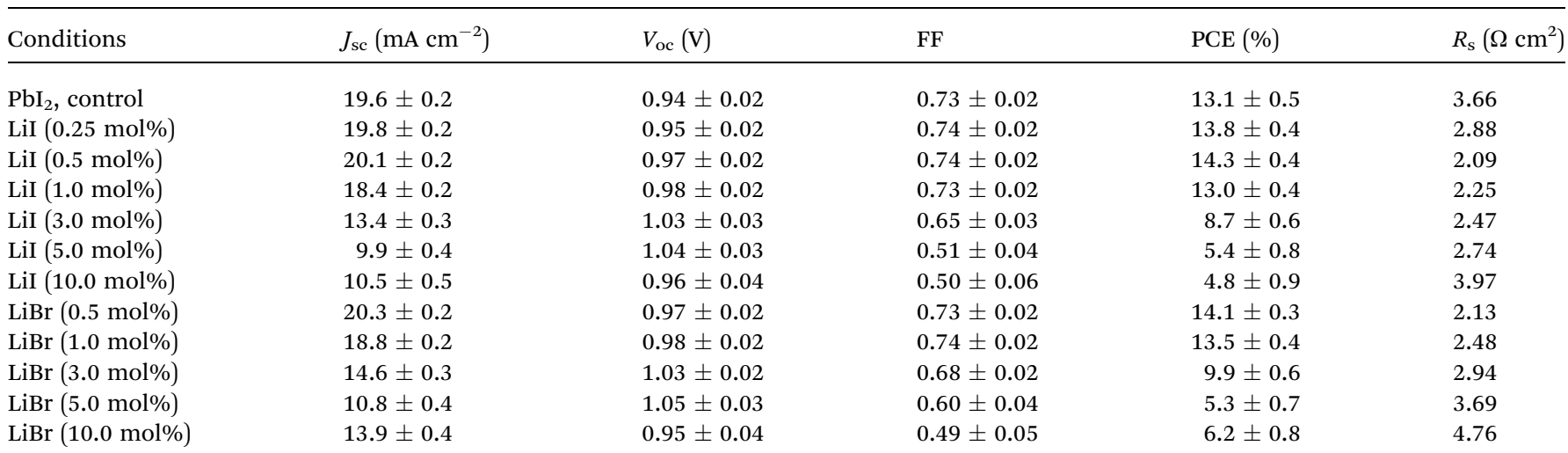




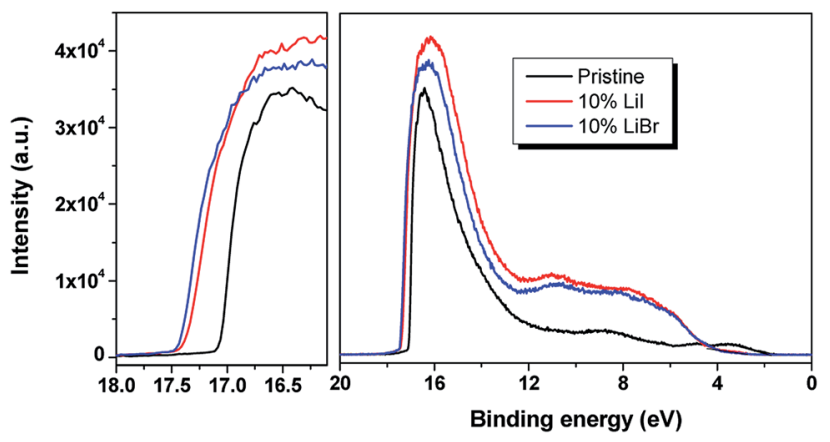

Fig. 4 UPS spectra of perovskite thin films without and with Li dopants.

To investigate the photophysical process associated with the $\mathrm{Li}$ in the perovskite phase, steady-state photoluminescence (PL) and time-resolved PL measurements were carried out on these thin films. From the steady-state PL, it could be observed that the $\mathrm{Li}$ incorporation slightly increased the PL intensity. Time-resolved PL was performed to probe the carrier lifetime of perovskite films prepared on glass substrates. Detailed information about the samples preparation, measurement, and fitting methodology can be found in the experimental part. The PL lifetime of the samples was fitted with a bi-exponential decay function which included a fast decay and a slow decay process. Generally, the radiative electron-hole recombination occurs by two different pathways with two different time scales contributing to the PL decay curves. The PL decay spectra of the samples are shown in Fig. 5b, and the related parameters are summarized in Table 2 . The fast decay lifetimes of the pristine perovskite film, $10 \mathrm{~mol} \%$ LiI doped perovskite film and $10 \mathrm{~mol} \% \mathrm{LiBr}$ doped perovskite film were $1.93 \mathrm{~ns}, 3.5 \mathrm{~ns}$ and $5.0 \mathrm{~ns}$, respectively, and the corresponding slow decay lifetimes of these three samples were $7.74 \mathrm{~ns}, 21.0 \mathrm{~ns}$, and $31.8 \mathrm{~ns}$, respectively. We have observed a larger PL yield and slower carrier lifetime in the $\mathrm{Li}$ doped samples, indicating a decreased nonradiative decay rate, which was likely due to a reduced defect density that suppressed nonradiative recombination.

These results can be further supported by femtosecond transient absorption spectroscopy and pump-probe measurements. Femtosecond transient absorption spectroscopy was performed to study the electron dynamics under
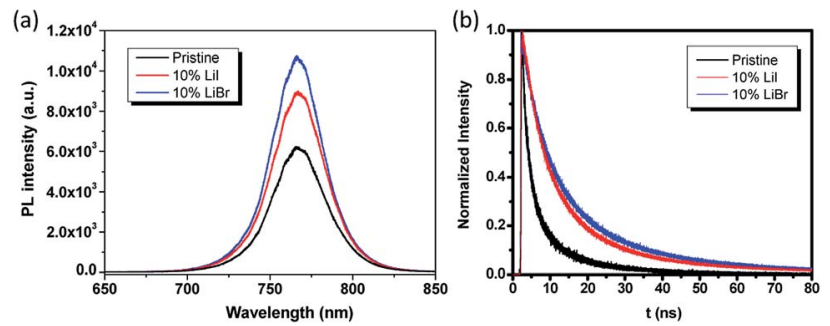

Fig. 5 Steady-state PL and time-resolved PL spectra for pristine and Li doped perovskite thin films on glass substrates.
Table 2 Fitted decay times of pristine and Li doped perovskite films

\begin{tabular}{llllcr}
\hline & Fraction 1 & $\tau_{1}(\mathrm{~ns})$ & Fraction 2 & $\tau_{2}(\mathrm{~ns})$ & $\tau_{\text {ave }}(\mathrm{ns})$ \\
\hline $0 \%$ & 0.47 & 1.93 & 0.53 & 7.74 & 6.68 \\
$10 \% \mathrm{LiI}$ & 0.61 & 3.5 & 0.39 & 21.0 & 17.34 \\
$10 \% \mathrm{LiBr}$ & 0.73 & 5.0 & 0.27 & 31.8 & 23.73
\end{tabular}

excitation of femtosecond laser pulses with wavelength centered at $500 \mathrm{~nm}$, pulse duration of $100 \mathrm{fs}$ and repetition rate of $500 \mathrm{~Hz}$. Fig. $6 \mathrm{a}-\mathrm{c}$ showed the transient absorption spectra of each films at different time delays. The transient absorption spectra of different perovskite films displayed similar profiles with two major features, a transient bleaching band and a photo-induced absorption band, indicating depopulating of the ground state and the presence of charge carriers. The LiBr doped perovskite film exhibited the highest transient bleaching intensity compared to the other two counterparts, while the pristine perovskite film showed the lowest intensity, which was consistent with the steady-state and time-resolved PL measurements, as the transient bleaching signal originated from the stimulated emission of the samples.

To monitor the evolution of the carriers upon optical excitation, the single wavelength dynamics probed at $720 \mathrm{~nm}$ were shown in Fig. 6d, giving a carrier lifetime of $176 \pm 4$ ps, $205 \pm 8$ ps and $305 \pm 10 \mathrm{ps}$ for pristine perovskite film, LiI doped perovskite film, and $\mathrm{LiBr}$ doped perovskite film, respectively. The presence of excess Li dopants led to rapid charge recombination, as evidenced by the rapid decay of the pristine perovskite film. While $10 \mathrm{~mol} \%$ LiI or LiBr doped perovskite film could reduce the amount of charge recombination at long timescales. The results of transient absorption spectroscopy and pump-probe measurements provided further support for the results and discussion in the previous sections.
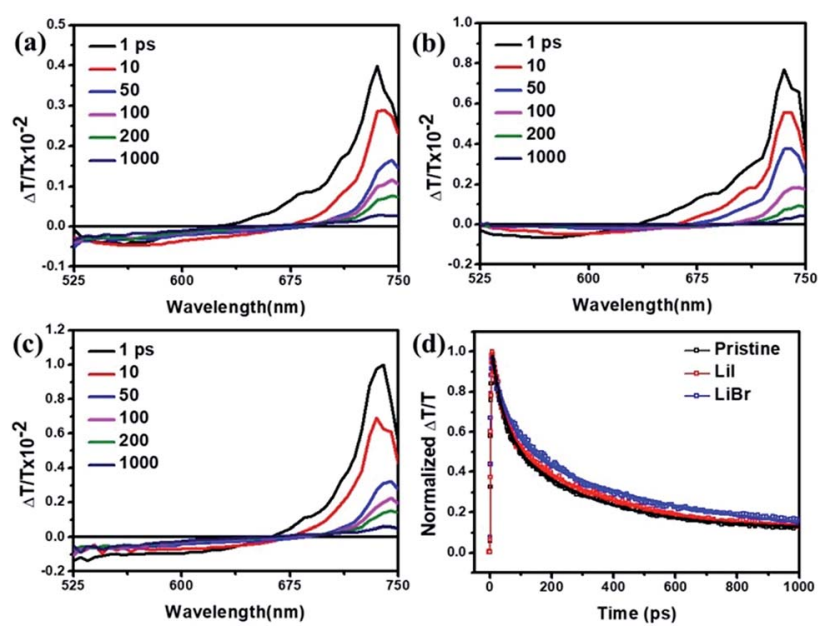

Fig. 6 Transient absorption spectra of for pristine perovskite film (a), Lil doped perovskite film (b), and $\mathrm{LiBr}$ doped perovskite film (c) under $500 \mathrm{~nm}$ excitation. (d) Single wavelength dynamics probed at $720 \mathrm{~nm}$ for different perovskite films. 


\section{Experimental}

\section{Materials and chemicals}

Patterned indium tin oxide (ITO) glass substrates $\left(10 \Omega \square^{-1}\right)$ were supplied by NSG group. Poly(3,4-ethy-lenedioxythiophene) poly(styrenesulfonate) (PEDOT:PSS, Clevios P VP Al 4083) was purchased from Heraeus Holding $\mathrm{GmbH}$. Methylammonium iodide (MAI) was obtained from Dyesol Ltd. [6,6]-Phenyl- $\mathrm{C}_{61^{-}}$ butyric acid methyl ester (PCBM) was bought from Nano-C Inc. Other materials, including lead(II) iodide ( $\mathrm{PbI}_{2}, 99.9 \%$ purity), lithium iodine (LiI, 99.999\% purity, anhydrous), lithium bromide (LiBr, 99.999\% purity, anhydrous), dimethyl sulfoxide (DMSO, anhydrous, $\geq 99.9 \%$ purity), $\gamma$-butyrolactone (GBL, $\geq 99 \%$ purity), chlorobenzene (anhydrous, 99.8\% purity), toluene (anhydrous, 99.8\% purity) were supplied by SigmaAldrich. All materials were used as received without further purification.

\section{Fabrication and characterization of perovskite solar cells}

ITO glass substrates were cleaned sequentially in detergent, deionized water, acetone, and isopropanol by sonication for 20 min each. After drying under $\mathrm{N}_{2}$ stream, substrates were further treated with UV-Ozone for $15 \mathrm{~min}$. A PEDOT:PSS layer with a thickness of $\sim 40 \mathrm{~nm}$ was prepared by spin coating PEDOT:PSS on ITO substrates at $7000 \mathrm{rpm}$ for $1 \mathrm{~min}$ and subsequently annealed at $140{ }^{\circ} \mathrm{C}$ for $15 \mathrm{~min}$ in air. The substrates with PEDOT:PSS were then transferred into a glove box filled with highly pure $\mathrm{N}_{2}$. The perovskite layer was formed by spin coating a solution consisting $1.4 \mathrm{M} \mathrm{PbI}_{2}$ and $1.4 \mathrm{M} \mathrm{MAI}+$ LiI (or LiBr) in co-solvent of DMSO : GBL (3: 7 vol. ratio) at $1000 \mathrm{rpm}$ for $20 \mathrm{~s}$, and then at $5000 \mathrm{rpm}$ for $60 \mathrm{~s}$. After $45 \mathrm{~s}$ of the start of the spin coating, $200 \mu \mathrm{l}$ toluene was dripped. Then, they were annealed at $100{ }^{\circ} \mathrm{C}$ for $10 \mathrm{~min}$. The thickness of the perovskite thin films was around $280 \mathrm{~nm}$. The PCBM layer with a thickness of about $60 \mathrm{~nm}$ was deposited by spin coating a chlorobenzene solution of $20 \mathrm{mg} \mathrm{mL}^{-1}$ PCBM at $1500 \mathrm{rpm}$ for $40 \mathrm{~s}$. The devices were completed by thermally deposition 100 $\mathrm{nm}$-thick $\mathrm{Ag}$ in a vacuum of $<1 \times 10^{-6}$ torr. Each device had an area of $0.075 \mathrm{~cm}^{2}$. The photovoltaic performance of the PSCs was tested in air with a computer-programmed Keithley 2400 source/meter and a Newport'sOriel class A solar simulator which simulated the AM1.5 sunlight with energy density of 100 $\mathrm{mW} \mathrm{cm}^{-2}$ and was certified to the JIS C 8912 standard. Incident photon-to-current conversion efficiencies (IPCEs) of PSCs were measured with a $300 \mathrm{~W}$ xenon lamp (Oriel 6258) and a Cornerstone 260 Oriel 74125 monochromator.

\section{Materials characterizations}

X-ray diffraction (XRD) spectra were acquired using a Bruker D8 Advance XRD Instrument. UV-vis absorption spectra were recorded with a Shimadzu UV-1800 spectrophotometer. Electron scanning microscopic (SEM) images were obtained with a Zeiss Supra-40 SEM. Film thickness was determined by a surface profilometer (KLATencor, Alpha-Step IQ). Ultraviolet photoelectron spectroscopy (UPS) spectra were acquired with a VG ESCA 220i-XL system. The UV source used was a He discharge lamp with a photon energy of $21.22 \mathrm{eV}$. Photoluminescence spectra were collected on an Edinburgh Instruments FLS920 spectrofluorometer, and the excitation wavelength was $633 \mathrm{~nm}$. For the time-resolved photoluminescence, the excitation source was a diode laser (NanoLED) working at a repetition rate of $10 \mathrm{MHz}$, with wavelength of $438 \mathrm{~nm}$ and pulse duration of $\sim 260 \mathrm{ps}$. The scattering of excitation light was eliminated by a two-600 $\mathrm{nm}$ long pass filter. Photoluminescence was collected and detected by an avalanche photon diode (Micro photon device, PicoQuant) attached to a time-correlated single photon counting card (TCSPC PicoHarp 300, PicoQuant). For the femtosecond transient absorption, the laser pulses generated from a mode-locked Ti:Sapphire oscillator seeded regenerative amplifier working at $800 \mathrm{~nm}$ with repetition rate of $1 \mathrm{kHz}$ and pulse duration of $50 \mathrm{fs}$. The $800 \mathrm{~nm}$ laser was splitted into two portions. A larger portion pumped an optical parametric amplifier (TOPAS, Light conversion) and generated the pump beam with wavelength of $500 \mathrm{~nm}$. A residual portion generated white light continuum in a $1 \mathrm{~mm}$ sapphire plate. The fluctuation of both pump and probe beams were cancelled out. The pump beam was focused onto the film with a beam size of $300 \mu \mathrm{m}$ and overlapped with a smaller diameter probe beam $\sim 100 \mu \mathrm{m}$. The time delay of the pump and probe laser pulse was varied by a computer controlled translational stage (Newport, ESP300). The pump beam was modulated by an optical chopper at a frequency of $500 \mathrm{~Hz}$. The variation transmittance at selected probe wavelength was recorded as a function of time delay between pump and probe pulses.

\section{Conclusions}

In conclusion, we have studied the $\mathrm{Li}$ incorporation effect on the $\mathrm{CH}_{3} \mathrm{NH}_{3} \mathrm{PbI}_{3}$ perovskite film formation, film crystallinity and morphology, charge carriers dynamic, as well as the solar cell device performance. It was found that within the threshold limit of $1.0 \mathrm{~mol} \%$ of $\mathrm{Li}$, the $\mathrm{Li}$ had positive effect on the perovskite film properties and corresponding device performance. However, solar cell devices exhibited significantly reduction upon 3 mol\% incorporation. Meanwhile, after further increasing the ratio to $10 \mathrm{~mol} \%$, the film totally changed, and the charge carrier lifetime was significantly enhanced compared to pristine film due to increased crystal size and reduced crystal defects. The Li doping mechanism was discussed, and it was thought to contain two different doping mechanisms. One is interstitial doping at much lower doping ratio, and another is substitutional doping for MA cation at higher doping ratio. This study highlights the possibility of inorganic cation doping as an efficient route for crystal construction and defect density control.

\section{Conflicts of interest}

There are no conflicts to declare. 


\section{Acknowledgements}

This work was financially supported by National Natural Science Foundation of China (61604119, 61704131), Natural Science Foundation of Shaanxi Province (2017JQ6002, 2017JQ6031), the Fundamental Research Funds for the Central Universities, and Young Talent fund of China Association for Science and Technology.

\section{Notes and references}

1 M. M. Lee, J. Teuscher, T. Miyasaka, T. N. Murakami and H. J. Snaith, Science, 2012, 338, 643-647.

2 A. Mei, X. Li, L. Liu, Z. Ku, T. Liu, Y. Rong, M. Xu, M. Hu, J. Chen, Y. Yang, M. Gratzel and H. Han, Science, 2014, 345, 295-298.

3 S. D. Stranks, G. E. Eperon, G. Grancini, C. Menelaou, M. J. P. Alcocer, T. Leijtens, L. M. Herz, A. Petrozza and H. J. Snaith, Science, 2013, 342, 341-344.

4 H. Zhou, Q. Chen, G. Li, S. Luo, T.-b. Song, H.-S. Duan, Z. Hong, J. You, Y. Liu and Y. Yang, Science, 2014, 345, 542-546.

5 J. Burschka, N. Pellet, S.-J. Moon, R. Humphry-Baker, P. Gao, M. K. Nazeeruddin and M. Grätzel, Nature, 2013, 499, 316319.

6 M. Liu, M. B. Johnston and H. J. Snaith, Nature, 2013, 501, 395-398.

7 D. Liu and T. L. Kelly, Nat. Photonics, 2013, 8, 133-138.

8 N. J. Jeon, J. H. Noh, Y. C. Kim, W. S. Yang, S. Ryu and S. Il Seok, Nat. Mater., 2014, 13, 897-903.

9 J. Chang, J. Xiao, Z. Lin, H. Zhu, Q.-H. Xu, K. Zeng, Y. Hao and J. Ouyang, J. Mater. Chem. A, 2016, 4, 17464-17472.

10 N. J. Jeon, J. H. Noh, W. S. Yang, Y. C. Kim, S. Ryu, J. Seo and S. Il Seok, Nature, 2015, 517, 476.

11 W.-Q. Wu, D. Chen, W. A. McMaster, Y.-B. Cheng and R. A. Caruso, ACS Appl. Mater. Interfaces, 2017, 9, 3195931967.

12 J. Chang, Z. Lin, H. Zhu, F. H. Isikgor, Q.-H. Xu, C. Zhang, Y. Hao and J. Ouyang, J. Mater. Chem. A, 2016, 4, 1654616552.

13 J. Chang, H. Zhu, J. Xiao, F. H. Isikgor, Z. Lin, Y. Hao, K. Zeng, Q.-H. Xu and J. Ouyang, J. Mater. Chem. A, 2016, 4, 7943-7949.

14 Z. Lin, J. Chang, J. Xiao, H. Zhu, Q.-H. Xu, C. Zhang, J. Ouyang and Y. Hao, Sol. Energy Mater. Sol. Cells, 2016, 157, 783-790.

15 Z. Zhou, S. Pang, Z. Liu, H. Xu and G. Cui, J. Mater. Chem. A, 2015, 3, 19205-19217.

16 W.-Q. Wu, H.-L. Feng, H.-Y. Chen, D.-B. Kuang and C.-Y. Su, J. Mater. Chem. A, 2017, 5, 12699-12717.

17 Z. Lin, J. Chang, H. Zhu, Q. H. Xu, C. Zhang, J. Ouyang and Y. Hao, Sol. Energy Mater. Sol. Cells, 2017, 172, 133-139.

18 J. T.-W. Wang, Z. Wang, S. Pathak, W. Zhang, D. W. DeQuilettes, F. Wisnivesky-Rocca-Rivarola, J. Huang, P. K. Nayak, J. B. Patel, H. A. Mohd Yusof, Y. Vaynzof, R. Zhu, I. Ramirez, J. Zhang, C. Ducati, C. Grovenor,
M. B. Johnston, D. S. Ginger, R. J. Nicholas and H. J. Snaith, Energy Environ. Sci., 2016, 9, 2892-2901.

19 NREL-National Renewable Energy Laboratory chart, http:// www.nrel.gov/ncpv/images/efficiency_chart.jpg, 2017.

20 J. Chang, H. Zhu, B. Li, F. Isikgor, Y. Hao, Q. Xu and J. Ouyang, J. Mater. Chem. A, 2016, 4, 887-893.

21 X. Sun, C. Zhang, J. Chang, H. Yang, H. Xi, G. Lu, D. Chen, Z. Lin, X. Lu, J. Zhang and Y. Hao, Nano Energy, 2016, 28, 417-425.

22 N. K. Noel, S. D. Stranks, A. Abate, C. Wehrenfennig, S. Guarnera, A. Haghighirad, A. Sadhanala, G. E. Eperon, S. K. Pathak, M. B. Johnston, A. Petrozza, L. Herz and H. Snaith, Energy Environ. Sci., 2014, 7, 3061-3068.

23 F. Hao, C. C. Stoumpos, R. P. H. Chang and M. G. Kanatzidis, J. Am. Chem. Soc., 2014, 136, 8094-8099.

24 W.-J. Yin, T. Shi and Y. Yan, Adv. Mater., 2014, 26, 4653-4658. 25 A. Dymshits, A. Rotem and L. Etgar, J. Mater. Chem. A, 2014, 2, 20776-20781.

26 J. H. Heo, D. H. Song and S. H. Im, Adv. Mater., 2014, 26, 8179-8183.

27 J. H. Noh, S. H. Im, J. H. Heo, T. N. Mandal and S. Il Seok, Nano Lett., 2013, 13, 1764-1769.

28 P.-W. Liang, C.-C. Chueh, X.-K. Xin, F. Zuo, S. T. Williams, C.-Y. Liao and A. K.-Y. Jen, Adv. Energy Mater., 2015, 5, 1400960.

29 L. Dimesso, M. Dimamay, M. Hamburger and W. Jaegermann, Chem. Mater., 2014, 26, 6762-6770.

30 J.-W. Lee, D.-J. Seol, A.-N. Cho and N.-G. Park, Adv. Mater., 2014, 6, 4991-4998.

31 S. Pang, H. Hu, J. Zhang, S. Lv, Y. Yu, F. Wei, T. Qin, H. Xu, Z. Liu and G. Cui, Chem. Mater., 2014, 26, 1485-1491.

32 N. Pellet, P. Gao, G. Gregori, T.-Y. Yang, M. K. Nazeeruddin, J. Maier and M. Grätzel, Angew. Chem., Int. Ed. Engl., 2014, 53, 3151-3157.

33 G. E. Eperon, S. D. Stranks, C. Menelaou, M. B. Johnston, L. M. Herz and H. J. Snaith, Energy Environ. Sci., 2014, 7, 982.

34 J. K. Nam, S. U. Chai, W. Cha, Y. J. Choi, W. Kim, M. S. Jung, J. Kwon, D. Kim and J. H. Park, Nano Lett., 2017, 17, 20282033.

35 F. Wu, J. T. Lee, N. Nitta, H. Kim, O. Borodin and G. Yushin, Adv. Mater., 2014, 27, 101-108.

36 S. a. Haque, T. Park, C. Xu, S. Koops, N. Schulte, R. J. Potter, a. B. Holmes and J. R. Durrant, Adv. Funct. Mater., 2004, 14, 435-440.

37 V. Thavasi, V. Renugopalakrishnan, R. Jose and S. Ramakrishna, Mater. Sci. Eng., R, 2009, 63, 81-99.

38 W. H. Nguyen, C. D. Bailie, E. L. Unger and M. D. McGehee, J. Am. Chem. Soc., 2014, 136, 10996-11001.

39 Y. Guo, C. Liu, K. Inoue, K. Harano, H. Tanaka and E. Nakamura, J. Mater. Chem. A, 2014, 2, 13827.

40 F. Giordano, A. Abate, J. P. Correa Baena, M. Saliba, T. Matsui, S. H. Im, S. M. Zakeeruddin, M. K. Nazeeruddin, A. Hagfeldt and M. Graetzel, Nat. Commun., 2016, 7, 10379. 41 M. R. Filip, G. E. Eperon, H. J. Snaith and F. Giustino, Nat. Commun., 2014, 5, 5757. 